\title{
SEM and TEM Characterization of Inorganic Atmospheric Particles in Air Quality Program.
}

\author{
R. Ramírez, Leal, H. E. Esparza and A. Duarte Moller \\ Centro de Investigación en Materiales Avanzados, S. C. \\ Miguel de Cervantes 120, Complejo Industrial Chihuahua \\ Chihuahua, Chih. 31109, Méxics
}

Different atmospheric aerosol samples were collected on SPT and PM10 filters during January 2003 to December 2004 from three zones in the city: The first one in the northwest, the second one in Downtown and third one to the northeast. The characterization of individual particles was completed by using a JEOL5800-LV scanning electron microscope combined with EDS and a Philips CM10 transmision electron microscope with an EELS attachment. Specimens were prepared by dispersing the samples from the filters onto alcohol and take us aliquot to pacing on sample holder.

The figures 1 and 2 show images SEM where observating individual particles from PM10 and SPT, respectivly, were classified the elements with EDS. The studies with EDS in SPT showing in all monitoring stations include compounds of $\mathrm{Al}, \mathrm{Ba}, \mathrm{Ca}, \mathrm{Ce}, \mathrm{Cl}, \mathrm{Cr}, \mathrm{Cu}, \mathrm{Fe}, \mathrm{K}, \mathrm{Mg}, \mathrm{Si}, \mathrm{Ti}, \mathrm{Zr}$. Only, two stations, Northeast and northwest, with Mo, S, V, Zn y W; in Towndown with Pb and Northwest with Br, La and $\mathrm{Na}$. With respect PM10 in the three stations we to find $\mathrm{Al}, \mathrm{Ca}, \mathrm{Cr}, \mathrm{Fe}$, $\mathrm{K}, \mathrm{Mg}, \mathrm{Na}, \mathrm{S}, \mathrm{Si}$ and Ti; northwest and northeast with $\mathrm{Zn}$; in the Downtown and northwest only $\mathrm{Pb}$ and for last Downtown were $\mathrm{Ce}, \mathrm{Cl}, \mathrm{Ni}, \mathrm{U}, \mathrm{V}$ and $\mathrm{Zr}$.

The results illustrate a distinct difference between those elements that were found to be highly abundant, how Al, $\mathrm{Si}, \mathrm{Ca}, \mathrm{Fe}, \mathrm{K}$ y Mg.Tthese elements tend to be associated with crustal or lithophilic sources such as agricultural activities, undisturbed soil, paved roads, unpaved roads and areas under construction.

An additional element, $\mathrm{Cl}$, is usually associated with combustión and incineration activities and salt aerosol. Other elements how $\mathrm{Ba}, \mathrm{Bi}, \mathrm{Cu}, \mathrm{Cr}, \mathrm{Mn}, \mathrm{Na}, \mathrm{Ni}, \mathrm{P}, \mathrm{Pb}, \mathrm{Ti}, \mathrm{V}$, and $\mathrm{Zn}$ are relationated with industrial and other anthropogenic activities. The other elements such as $\mathrm{V}$ and $\mathrm{S}$ are indicative of oil combustion and regional sulphates.

The rare earth elements how $\mathrm{Ce}$ and La showed associated with $\mathrm{P}$ suggesting are common accessory mineral in plutonic and sedimentary rocks.

A $\mathrm{Zr}$ bearing was observed in association with slighly smaller Fe-Ti particles at the surface of a Ca-Al- Silicate.T o establish air quality how good or bad based in normal analysis, to be to hide the action of many elements in atmospheric particles with low concentrations, but size able to exert important adverse health on population. Finally in Figure 3 appears a PM10 particle when the Cs is present as show the EELS spectrum in Figure 4.

\section{References}

1.- Buseck, P., D. J. Jacob, M. Pósfai, J. Li, and J. R. Anderson.. Minerals in the Air: An Env. Persp.. Int. Geol. Rev. 42: 1-17 2000

2.- Chong, N., K. Sivaramakrishnan, M. Wells, and K. Jones.. J. Environ. Agric. Food Chem. 1(3): $1-202002$ 
3.- Gavett, S. H., N. Haykal-Coates, L. B. Copeland, J. Heinrich, and M. I. Gilmour.. Environ. Health Persp. 111 (12): 1471-14772003

4.- Utsunomiya, S., K. A. Jensen, G. J. Keeler and R. C. Ewing.. Env. Sci. \& Technol. 38 (8): 2289-22972004

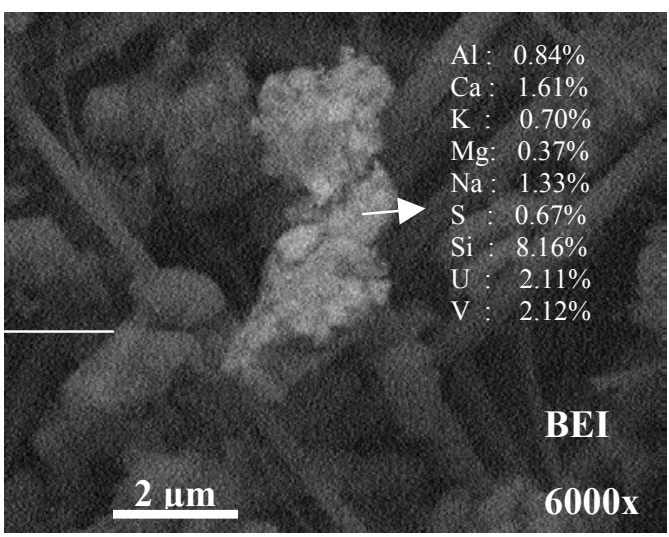

Figure 1.Image Particle from PM10

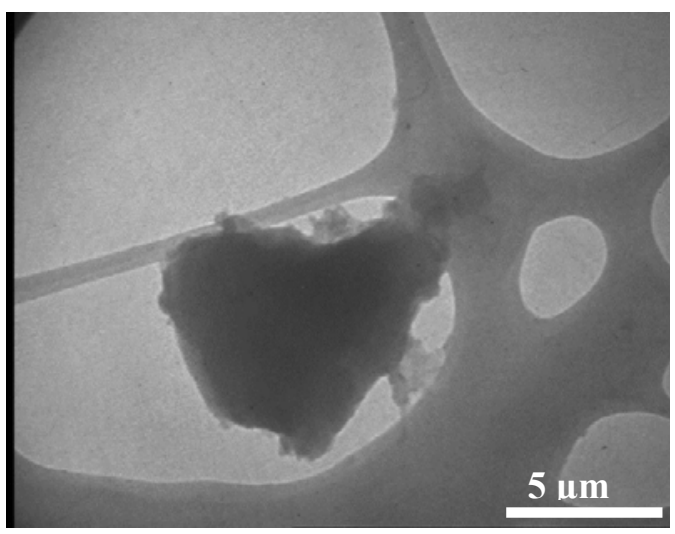

Figur 3. TEM image of PM10 particle containig $\mathrm{Cs}$

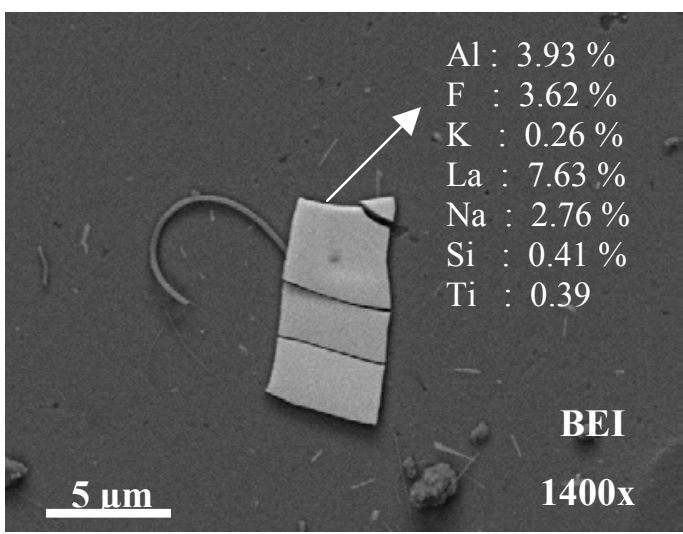

Figure 2. Image Particle from SPT

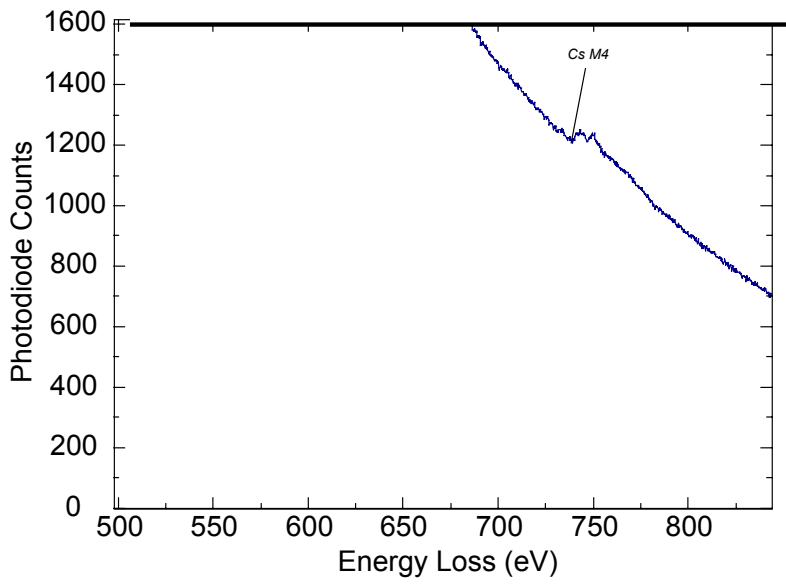

Figure 4. EELS spectrum of the PM10 particle when the $\mathrm{M}_{4} \mathrm{Cs}$ transition appear.

Acknowledgments

We thanks to Dr. Francisco Paraguay Delgado for his technical help in this work. 